\title{
Thyroglossal Duct Cyst in Elderly Patient
}

\author{
Allouch Ihssane*, H. Ait Taleb, N. Belhaj, R. Bencheikh, M.A. Benbouzid, L. Essakalli
}

Service ORL et CCF de l’hôpital des spécialités de Rabat, CHU Rabat Salé

DOI: $10.36347 /$ simcr.2021.v09i01.027

| Received: 13.01.2021| Accepted: 25.01.2021| Published: 30.01.2021

*Corresponding author: Allouch Ihssane

Abstract

Case Report

Introduction: Thyroglossal duct cysts are the most common congenital neck cysts .About $50 \%$ of the cases are detected within the first 2 decades of life, but can also appear later in adult life. Case report: This is a 57-year-old male patient followed for urothelial bladder carcinoma with a cervical mass that has been evolving for more than 20 years without signs of compression of adjacent organs. The examination noted a large anterior cervical swelling $16 \mathrm{~cm}$ in diameter, of firm consistency, painless and motionless on swallowing, the skin opposite the mass is healthy. The CT appearance is suggestive of a Thyroglossal Duct Cyst or a laryngocele. Exploratory cervicotomy found a superficial cystic mass, adherent to the body of the hyoid bone, strongly suspecting the possibility of a Thyroglossal Duct Cyst. The surgical excision was performed using the Sistrunk technique, removing the cyst en bloc with the body of the hyoid bone. And sent the specimen for histopathological evaluation, which confirmed per-operative diagnosis. Conclusion: The cyst of the thyroglossal tract is a common pathology in children, but remains rare in adults. The challenge of treatment is to know how to think about it in front of a cervical mass.

Keywords: Thyroglossal congenital pathology.

Copyright $(\mathcal{C} 2021$ The Author(s): This is an open-access article distributed under the terms of the Creative Commons Attribution 4.0 International License (CC BY-NC 4.0) which permits unrestricted use, distribution, and reproduction in any medium for non-commercial use provided the original author and source are credited.

\section{INTRODUCTION}

Thyroglossal duct cysts are the most common congenital neck cysts accounting for $70 \%$ of the cases. About $50 \%$ of the cases are detected within the first 2 decades of life, but approximately $15 \%$ of cases are diagnosed after the age of 50 years. Both sexes are equally affected. Most thyroglossal duct cysts are slow growing, averaging a size of $2-4 \mathrm{~cm}$, but may enlarge rapidly following an upper respiratory tract infection [1].

We present a rare case of TGDC occurring in an elderly subject after reaching a huge size

\section{Clinical Case}

This is a 57-year-old male patient followed for urothelial bladder carcinoma with a cervical mass that has been evolving for more than 20 years without signs of compression of adjacent organs. The examination noted a large anterior cervical swelling $16 \mathrm{~cm}$ in diameter, firm, painless and motionless on swallowing. The skin opposite the mass is healthy. On the axial section of the cervical CT (fig a), we visualized an anterior cervical formation measuring $65 \times 163 \mathrm{~mm}$ with impure liquid content, thin-walled, coming into contact with hyoid bone and thyroid cartilage bulging slightly at the level of the larynx. The CT appearance is suggestive of a Thyroglossal Duct Cyst or a laryngocele. Exploratory cervicotomy (fig b) performed under general anesthesia, found a superficial cystic mass, adherent to the body of the hyoid bone, strongly suspecting the possibility of a Thyroglossal Duct Cyst. The surgical excision was performed using the Sistrunk technique, removing the cyst with the body of the hyoid bone. The specimen was sent for histopathological evaluation.

\section{ReSUlTS}

The patient wound healed adequately with no complications. Histological study of the surgical specimen confirmed the diagnosis of Thyroglossal Duct Cyst and no thyroid tissue; no recurrence after two and a half years. 


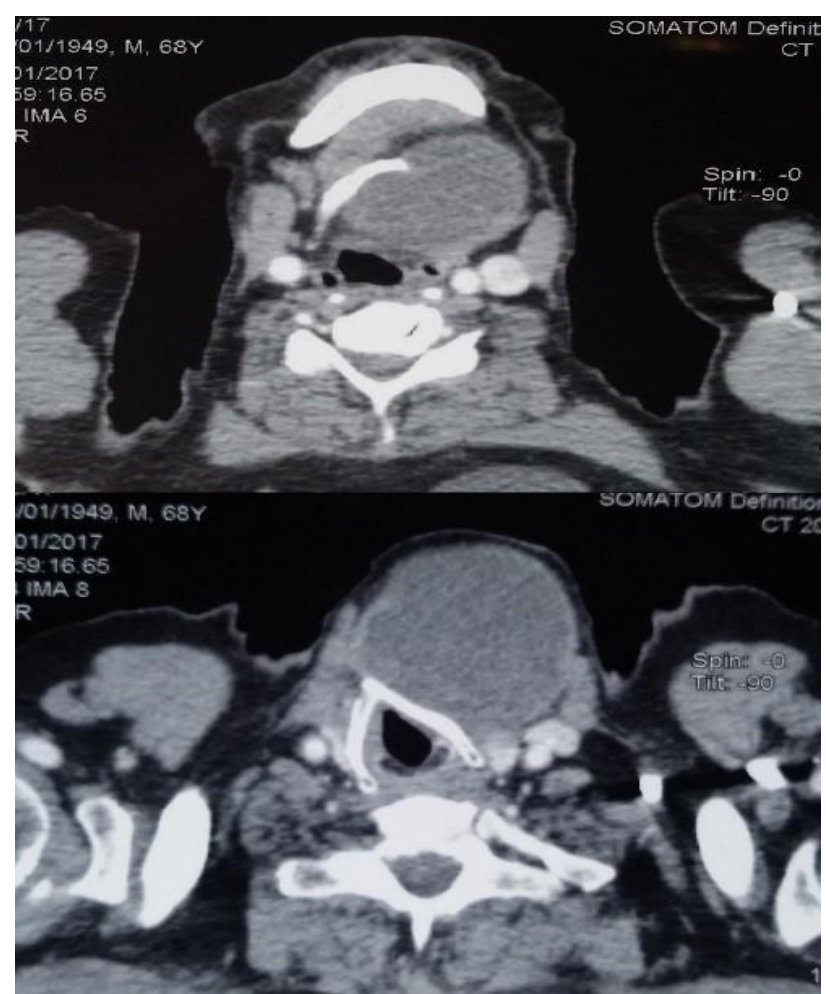

Fig-a: Axial section of the cervical CT showing an anterior cervical formation measuring $65 \times 163 \mathrm{~mm}$ with impure liquid content

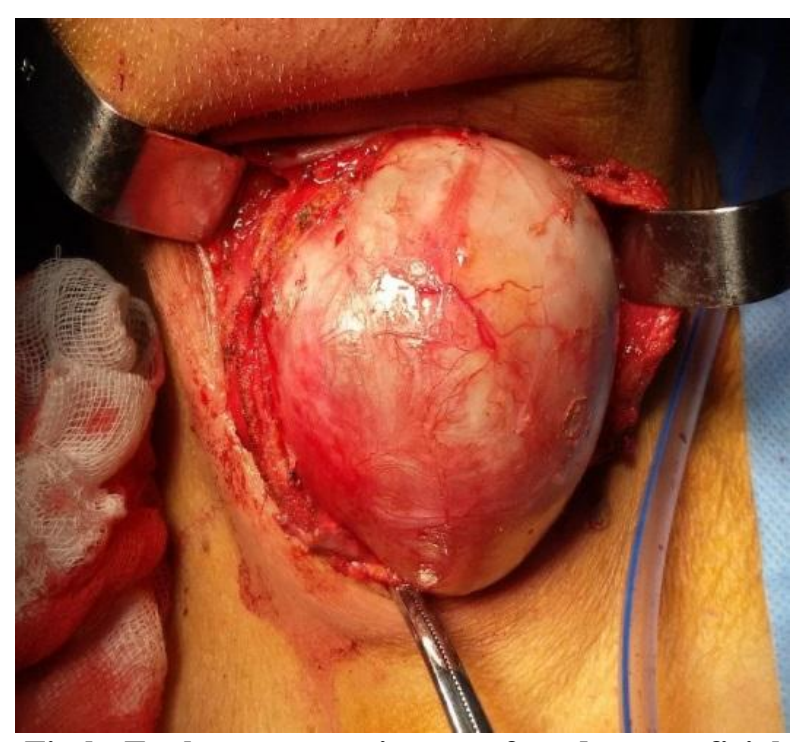

Fig-b: Exploratory cervicotomy found a superficial cystic mass adherent to the body of the hyoid bone

\section{DiscUSSION}

Neck cysts are birth defects resulting from an abnormality during embryonic development. It is a frequent reason for consultation in pediatrics (12 to $25 \%$ of the causes of cervical swelling), but can also be found in adults. About 7\% of adults have a Thyroglossal Duct Cyst [2]. The Thyroglossal Duct Cyst is the result of an embryological migration abnormality of the thyroid. The thyroglossal tract corresponds to the area of migration of the thyroid through the base of the tongue, towards the lesser horns of the hyoid bone and then to the level of the anterior cervical level [3]. Cysts of the thyroglossal duct appear clinically as median cervical masses located in $50 \%$ of cases opposite to the hyoid bone, in $25 \%$ of cases above the hyoid bone; finally, in the remaining $25 \%$ of cases, they are located below the hyoid bone, in the middle or paramedian position. It is most often a painless lump that progresses gradually in a child or young adult. It may appear during episodes of infection. Exceptionally, it can be associated with thyroid carcinoma [4].

Imaging workup is essential before surgery. Indeed, the ultrasound will confirm the cystic nature of the lesion, but above all will ensure the existence of a thyroid gland in a normal position. Indeed, if the cyst constituted the only ectopic remnant of thyroid tissue, its removal would lead to postoperative hypothyroidism [3].

The CT scan identifies a well-individualized cystic mass, sometimes with intracystic septa. The injection of contrast medium may reveal a slight peripheral enhancement, which is more pronounced in case of infection. If there is an associated thyroid carcinoma, it may present as an eccentric mass with calcifications within it [4].

The gold standard for thyroglossal duct surgery is the Sistrunk technique which is based on the embryological work of Wenglowski and which recommends the resection of the body of the hyoid bone. The cyst usually adheres to the lower part of the hyoid bone, it is resected in one piece with the cyst, 
Allouch Ihssane et al., Sch J Med Case Rep, Jan, 2021; 9(1): 103-105

taking the body away, after freeing it from its upper and lower muscle attachments. The bone is cut between the 2 Lesser horns that were previously released, as well as its deep face. The basilingual tract is very rarely individualizable. The dissection is made down to the level of the lingual mucosa. The tract is ligated before being severed [5].

The thyroglossal duct cyst is defined from an anatomopathological point of view by a linear epithelium of the wall sometimes squamous, sometimes glandular, inconstantly associated with normal thyroid follicles. Malignant degeneration on remains of the tract represents $1 \%$ of the operated cysts the diagnosis is most often made postoperatively, following the pathological study of the operative specimen [6].

Recurrence is the most frequent complication : it occurs in $1.5 \%$ to $10 \%$ of cases on average in the different series. This recurrence rate increases in patients operated in the inflammatory phase [5].

\section{CONCLUSION}

The cyst of the thyroglossal tract is a common pathology in children, but remains rare in adults. The challenge of treatment is to know how to think about it in front of a cervical mass, and to ensure that the differential diagnoses have been eliminated, in particular lymphadenopathy of cancerous origin.
The treatment consists of complete surgical excision, the only guarantee of the absence of recurrence.

\section{Declaration of links of interest}

The authors declare that they have no links of interest

\section{REFERENCES}

1. Pincus RL: Congenital neck masses and cysts. In: Bailey BJ, Johnson JT, Newlands SD (eds.) Head and neck surgery - otolaryngology. 4th ed. Vol. 1. Philadelphia: Lippincott William and Wilkins. 2006; 1209-16

2. Ballivet de Régloix S, Maurin O, Crambert A. Kystesetfistulescongenitaux du cou chez l'adulte. Presse Med. 2019;48:29-33.

3. Leloup P, Malard O, Stalder J-F. Kystesetfistulescongénitaux de la face et du cou. Annales de dermatologieet de vénéréologie. 2012;139:842-851.

4. Teissier N, Bois E. Fistulesetkystescongénitaux du cou. EMC - Oto-rhino-laryngologie. 2017;13(2):119.

5. Righini C-A, Hitter A, Reyt E. Chirurgie du tractusthyréoglosse. Technique de Sistrunk. Annalesfrançaisesd'oto-rhino-laryngologieet de pathologiecervico-faciale. 2016;133:120-123.

6. Ghfir I, Ouboukdir R, M'Hamdi F. Kyste du tractusthyréoglossedégénérérévélantunmicrocarcin omepapillaire multifocal de la thyroide. MédecineNucléaire. 2010;34:e29-e33. 